\title{
STUDI EKSPERIMEN KARAKTERISTIK SHELL-AND-TUBE HEAT EXCHANGER DENGAN VARIASI JENIS BAFFLE DAN JARAK ANTAR BAFFLE
}

\author{
Teguh Hady Ariwibowo*, Prima Dewi Permatasari, \\ Novan Ardhiyangga, Sugit Triyono \\ Program Studi Sistem Pembangkit Energi, DTME \\ Politeknik Elektronika Negeri Surabaya \\ Kampus PENS, Sukolilo, Surabaya 60111 \\ ${ }^{*}$ e-mail : teguhhady@pens.ac.id
}

\begin{abstract}
ABSTRAK
Shell-and-Tube Heat Exchanger merupakan jenis penukar kalor yang banyak digunakan di pembangkit dan pengolahan minyak. Namun, peningkatan performa penukar kalor ini perlu dilakukan dengan cermat karena alirannya yang kompleks didalam shell. Penelitian ini mengkaji peningkatan performa dalam bentuk koefisien perpindahan panas total dan efektivitas dengan melakukan variasi jenis baffle (single segmental dan triple segmental) dan baffle spacing (5 $\mathrm{cm}$ dan $10 \mathrm{~cm}$ ) menggunakan pendekatan eksperimen dan numerik. Penukar kalor diuji pada laju massa 0,033; 0,066; 0,099; 0,133; dan 0,166 kg/s. Pada variasi jenis baffle, hasil eksperimen menunjukkan single segmental menghasilkan koefisien perpindahan panas total dan efektivitas yang lebih baik dari pada triple segmental dengan nilai koefisien perpindahan panas total maksimal $301 \mathrm{~W} / \mathrm{m}^{2} . \mathrm{K}$ pada $0,166 \mathrm{~kg} / \mathrm{s}$ dan efektivitas maksimal 0,5 pada $0,033 \mathrm{~kg} / \mathrm{s}$. Sedangkan, pada variasi baffle spacing, hasil eksperimen menunjukkan baffle spacing $5 \mathrm{~cm}$ menghasilkan koefisien perpindahan panas maksimal $651 \mathrm{~W} / \mathrm{m}^{2} . \mathrm{K}$ saat laju massa $0,166 \mathrm{~kg} / \mathrm{s}$ sedangkan baffle spacing ini hanya munjukkan performa yang lebih besar dari baffle spacing $10 \mathrm{~cm}$ ketika laju massa $0,133 \mathrm{~kg} / \mathrm{s}$. Hasil simulasi menunjukkan turbulensi aliran yang besar pada sisi shell mengakibatkan distribusi temperatur merata sehingga mempengaruhi koefisien perpindahan panas total.
\end{abstract}

Kata Kunci : Shell-and-Tube Heat Exchanger, baffle spacing, jenis baffle, koefisien perpindahan panas total, efektivitas, CFD.

\begin{abstract}
ABSTRACK
Shell-and-Tube Heat Exchanger is sort of heat exchanger commonly applied in power plants and oil refineries. However, improved performance of this equipment requires being carried out cautiously because of flow ramification inside shell. This study examines performance improvement in total heat transfer coefficient and effectiveness by variations in type of baffles (single and triple segmental) and baffle spacing $(5 \mathrm{~cm}$ and $10 \mathrm{~cm})$ using experimental and numerical approach. Heat exchanger was assessed at mass rate 0,$033 ; 0,066 ; 0.099 ; 0.133$; and $0.166 \mathrm{~kg} / \mathrm{s}$. In variations of type of baffles, experimental outcome presented single segmental baffle brought about better total heat transfer coefficient and effectiveness than the triple segmental baffle maximum total heat transfer coefficient $301 \mathrm{~W} / \mathrm{m} 2 . \mathrm{K}$ at $0.166 \mathrm{~kg} / \mathrm{s}$ and maximum effectiveness 0.5 in $0.033 \mathrm{~kg} / \mathrm{s}$. Meanwhile, the baffle spacing variations, experimental results depicted baffle spacing $5 \mathrm{~cm}$ produced maximum total heat transfer coefficient of $651 \mathrm{~W} / \mathrm{m} 2 . \mathrm{K}$ at mass rate $0.166 \mathrm{~kg} / \mathrm{s}$ while baffle spacing $5 \mathrm{~cm}$ was solely performed better than the baffle spacing $10 \mathrm{~cm}$ at mass rate $0.133 \mathrm{~kg} / \mathrm{s}$. The simulation results illustrated that turbulent flow inside shell resulting in uneven temperature distribution which contributed on total heat transfer coefficient increment.
\end{abstract}

Key Words : Shell-and-Tube Heat Exchanger, baffle spacing, sort of baffle, total heat transfer coefficient increment, effectiveness, CFD. 


\section{PENDAHULUAN}

Shell-and-tube heat exchanger (STHX) banyak diaplikasikan di industri seperti pembangkit listrik, kilang minyak, pengolahan makanan dsb. Master, dkk (2003) menyatakan bahwa lebih dari 35-40\% penukar kalor adalah tipe STHX dikarenakan kekuatan konstruksi geometri, kemudahan perawatan dan peluang upgrade. Baffle merupakan komponen penting dari STHX. Selain berfungsi menyuport tube bundle, baffle membentuk aliran pada sisi shell. Jenis baffle yang paling banyak dipergunakan adalah segmental baffle yang memaksa aliran di dalam sisi shell mengalir zigzag untuk meningkatkan perpindahan panas namun dengan konsekuensi pressure drop tinggi Sekarang, Tipe penukar kalor ini banyak dikembangkan dan mungkin masih umum dipergunakan sebagai STHX (Bell 1981; Bell 1986; Bell 1988; Bell 2004). Koefisien perpinpindahan panas sisi shell lebih kompleks daripada sisi tube dikarenakan banyak faktor yang mempengaruhi (Serth, 2007).

Kinerja STHX dipengaruhi oleh beberapa parameter. Beberapa parameter tersebut adalah efektivitas dan koefisien pepindahan panas. Beberapa cara untuk meningkatkan performa ini adalah menggunakan tipe baffle serta mengatur jarak antar baffle (baffle spacing). Šoljic dkk. (2009) membandingkan karakter aliran dengan menggunakan beberapa baffle, baffle tersebut adalah tipe single segmental dan triple segmental. Hasil penelitian ini adalah triple segmental baffle memiliki nilai vortex shedding frequency lebih rendah dari pada single segmental baffle. Nilai vortex shedding frequency ini mempengaruhi besar vibrasi di STHX. Disamping itu, baffle tipe triple segmental menghasilkan penurunan tekanan yang lebih rendah dari pada single segmental baffle.

Ardhiyangga dkk (2016) yang mengamati karakteristik aliran didalam STHX dengan pendekatan simulasi numerik 1-Dimensi menggunakan software HTRI serta menyimpulkan bahwa terjadi peningkatan koefisien perpindahan panas sisi shell dan efektivitas jika meningkat jika laju massa ditingkatkan. Sedangkan, pengamatan HTRI juga dilakukan oleh Triyono dkk (2016) untuk mengamati pengaruh baffle spacing terhadap koefisien perpindahan panas total STHX menyimpulkan bahwa pada rasio heat capacity yang sama $\left(\mathrm{C}^{*}=1\right)$ didapatkan baffle spacing yang lebih pendek menghasilkan koefisien perpindahan panas total lebih besar dari pada baffle spacing lebih jauh. Tetapi, penggunaan pendekatan metode 1-Dimensi tidak mampu memaparkan secara jelas turbulensi aliran yang mempengaruhi performa perpindahan panas.

Oleh karena itu, penelitian ini mengamati pengaruh jenis baffle dan jarak antar baffle terhadap kinerja serta karakteristik aliran dalam STHX secara eksperimen serta menggunakan metode numerik Computational Fluid Dynamics (CFD) untuk menyimulasikan secara 3-Dimensi yang hanya untuk mengetahui kondisi aliran yang ada di dalam STHX serta mengorelasikannya dengan hasil eksperimen. Untuk variasi jenis baffle, baffle yang digunakan adalah single segmental dan triple segmental.

\section{METODE PENELITIAN}

\subsection{Penyetingan STHX dan alat pengujian}

Penilitian ini dilakukan melakukan uji eksperimen STHX pada laju massa 0,033; 0,066; 0,099; 0,133; dan 0,166 kg/s di Laboratorium Termofluida Program Studi Sistem Pembangkit Energi DTME Politeknik Elektronika Negeri Surabaya. Adapun Spesifikasi STHX yang digunakan sebagai berikut diameter internal shell $16 \mathrm{~cm}$, panjang shell 50 $\mathrm{cm}$, panjang header $10 \mathrm{~cm}$, diameter luar tube $1 / 2$ in, jumlah tube 30 , tebal tube $2 \mathrm{~mm}$, 
jumlah segmental baffle 4 (single segmental), jumlah segmental baffle 10 (triple segmental). Bahan shell terbuat dari stainless steel agar tidak mudah korosi sedangkan material pada tube menggunakan tembaga karena konduktivitas termal yang tinggi sehingga dapat mempercepat proses perpindahan panas. Baffle terbuat dari aluminium untuk mempermudah proses fabrikasi. Gambar 1 menunjukkan variasi baffle spacing dengan baffle cut sebesar 25\%. Baffle spacing yang dipilih yaitu $5 \mathrm{~cm}$ dan $10 \mathrm{~cm}$. Penelitian ini terdapat kesamaan antara variasi baffle spacing dan jenis baffle yaitu pada single segmental baffle yang memiliki baffle spacing $10 \mathrm{~cm}$.

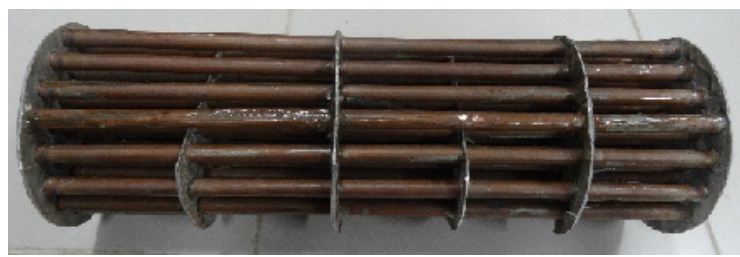

(a)

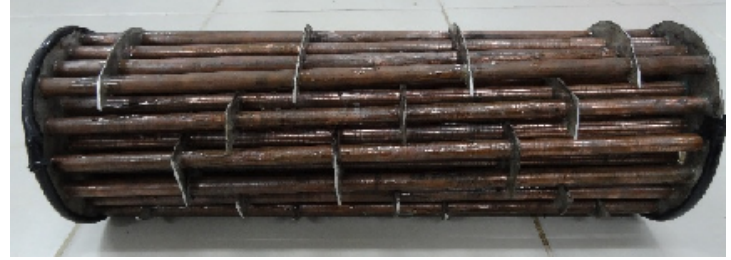

(b)

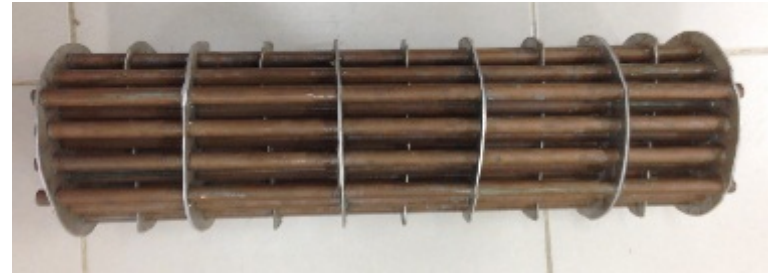

(c)

Gambar 1. Pemasangan baffle pada tube bundle (a) single segmental baffle (dengan baffle spacing $5 \mathrm{~cm}$ ) (b) triple segmental baffle (c) baffle spacing $10 \mathrm{~cm}$

Gambar 1. (a) menunjukkan hasil fabrikasi single segmental baffle yang terintagrasi dengan tube bundle dengan nilai baffle cut sebesar 31,25\%. Jumlah baffle yang tersusun 4 buah dengan jarak antar baffle sebesar $10 \mathrm{~cm}$. Gambar 1. (b) menunjukkan 3 buah segmen baffle yang terintegrasi dengan tube bundle dengan jarak antar baffle sebesar 4,46 $\mathrm{cm}$. Sudut antar tube $45^{\circ}$ tube pitch $2,5 \mathrm{~cm}$, jumlah tube keseluruhan 30 buah diameter tube bundle $16 \mathrm{~cm}$. Sedangkan, Gambar 1 (a) dan (c) menjukkan jarak antar baffle $5 \mathrm{~cm}$ dan $10 \mathrm{~cm}$. 


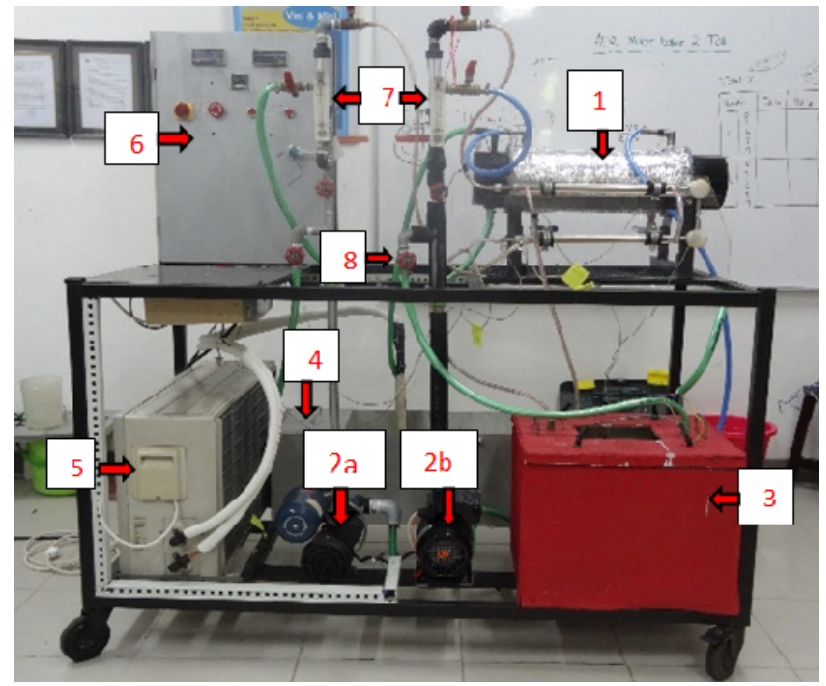

(a)

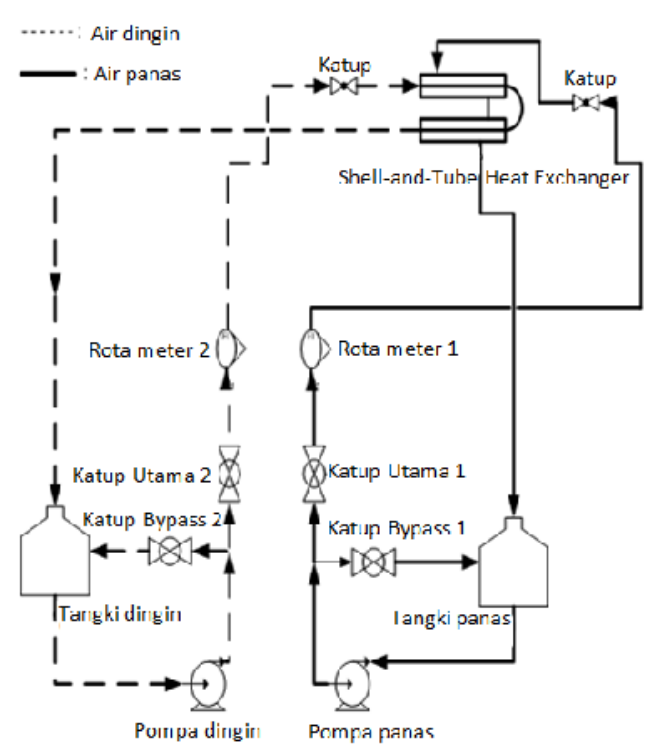

(b)

Gambar 2. (a) Setting Alat Uji (b) Diagram Alir Proses

Eksperimen yang dilakukkan sebuah unit STHX dengan beberapa komponen pendukung, ditunjukkan pada Gambar 2 (a) dan diagram alir proses sistem uji dapat dilihat di Gambar 2 (b). Adapun sistem pengujian unit STHX dapat dilihat pada Tabel 1.

Tabel 1. Spesifikasi Sistem Penujian

\begin{tabular}{|c|l|l|}
\hline No & \multicolumn{1}{|c|}{ Nama } & \multicolumn{1}{c|}{ Spesifikasi } \\
\hline 1 & Unit STHX & Dimensi $\mathrm{p}: 170 \mathrm{~cm}$ diameter $: 16 \mathrm{~cm}$ \\
\hline 2 & Pompa Air & $\begin{array}{l}\text { a. Merk Panasonic } 18 \text { lpm dengan daya } 125 \mathrm{~W} \text { ( Cold Pump) } \\
\text { b. Merk CNP } 28 \mathrm{~m}^{3} / \mathrm{h} \text { dengan daya 370W (Hot Pump) }\end{array}$ \\
\hline 3 & Tandon air panas & Dimensi $: 50 \times 40 \times 40 \mathrm{~cm}$ \\
\hline 4 & Tandon air dingin & Dimensi $: 120 \times 30 \times 30 \mathrm{~cm}$ \\
\hline 5 & Air Conditioning & Merk National $1,5 \mathrm{PK}$ \\
\hline 6 & Panel control & 1 Unit \\
\hline 7 & Flow meter & Rotameter kapasitas maksimum $18 \mathrm{lph}$ \\
\hline 8 & Pipa koneksi & $1 / 2$ inch \\
\hline 9 & Valve & Ball valve $1 / 2$ inch dan Gate valve $1 / 2$ inch \\
\hline 10 & Heater & 2 Heater air, masing-masing $1,5 \mathrm{KW}$ \\
\hline 11 & Sensor Temperatur & Termocouple tipe K \\
\hline
\end{tabular}

Tahap pertama, air panas dan dingin diletakkan pada tangki terpisah. Pada tangki panas, heater elektrik dipasang untuk menjaga teperatur air panas konstan. Heater ini dikendalikan oleh thermocontrol sehingga temperatur air panas dapat dijaga. Begitu juga dengan tangki dingin, evaporator sebuah air conditioning dipasang untuk menjaga temperatur air dingin dapat dijaga. Kemudian, air panas dan dingin dipompa menuju unit STHX. Air panas dialirkan disisi shell sedangkan air dingin dipompa disisi tube. Debit aliran diukur menggunakan rotameter yang terpasang. Debit air yang berlebih diatur dengan katup bypass. Debit yang terukur dikonversi ke laju aliran massa yang dihitung dengan mengalikan massa jenis dengan debit.

\subsection{Pemrosesan Data}

Sebelum melakukan pemrosesan data, properti air perlu yang perlu dicari adalah Heat capasity $\left(\mathrm{c}_{\mathrm{p}}\right)$, viscosity fluid $(\mu)$, Thermal conductivity $(\mathrm{k})$ yang diambil sesuai dengan 
temperatur rata-rata sisi inlet dan outlet STHX. Kalor air dingin $\left(\mathrm{q}_{\mathrm{c}}\right)$ dan air panas $\left(\mathrm{q}_{\mathrm{h}}\right)$ dapat dihitung menggunakan persamaan (1) dan (2).

$$
\begin{aligned}
& q_{c}=\dot{m}_{c} c_{p c} \Delta T_{c} \\
& q_{h}=\dot{m}_{h} c_{p h} \Delta T_{h}
\end{aligned}
$$

Selanjutnya mencari log mean temperature difference (LMTD) atau bisa disebut dengan

$\mathrm{T}_{\mathrm{lm}}$, dengan terlebih dahulu mencari nilai correction faktor $(\mathrm{F})$, Maka dapat menggunakan persamaan 3 .

$$
\Delta T_{l m}=F\left(\Delta T_{l n}\right)_{c f}
$$

Nilai F diperoleh dari persamaan berikut

$$
F=\frac{\sqrt{R^{2}+1} \ln \left(\frac{1-S}{1-R S}\right)}{(1-S) \ln \left[\frac{2-S\left(R+1-\sqrt{R^{2}+1}\right)}{2-S\left(R+1+\sqrt{R^{2}+1}\right)}\right]}
$$

Nilai S diperoleh dari persamaan (5)

$$
S=\frac{\alpha-1}{\alpha-R}
$$

Nilai $\alpha$ dicari dengan persamaan (6). $\mathrm{N}$ merupakan jumlah laluan sisi shell.

$$
\alpha=\left(\frac{1-R P}{1-P}\right)^{1 / N}
$$

Kemudian, $\mathrm{R}$ dan $\mathrm{P}$ dihitung dengan persamaan (7) dan (8).

$$
\begin{gathered}
R=\frac{T_{a}-T_{b}}{t_{a}-t_{b}} \\
P=\frac{t_{b}-T_{a}}{T_{a}-t_{a}}
\end{gathered}
$$

Dimana $\mathrm{T}_{\mathrm{a}}$ merupakan temperatur inlet sisi shell, $\mathrm{T}_{\mathrm{b}}$ merupakan teperatur outlet sisi shell, $\mathrm{t}_{\mathrm{a}}$ merupakan temperatur inlet sisi tube, dan $\mathrm{t}_{\mathrm{b}}$ merupakan temperatur outlet sisi tube. Sedangkan perhitungan koefisien perpindahan panas total dilakukan dengan mengasumsikan aliran tidak mengakibatkan fouling sehingga dapat dihitung dengan persamaan (9)

$$
U c=\left[\frac{D o}{h i D i}+\frac{D o \ln \left(\frac{D o}{D i}\right)}{2 k}+\frac{1}{h o}\right]^{-1}
$$

Dimana $U_{c}$ merupakan koefsien perpindahan panas total tanpa fouling, $\mathrm{D}_{\mathrm{o}}$ merupakan outer diameter dari tube, $\mathrm{D}_{\mathrm{i}}$ merupakan inner diameter dari tube, $\mathrm{k}$ merupakan koefisien konduksi tube. Nilai koefisien perpindahan panas sisi tube $\left(\mathrm{h}_{\mathrm{i}}\right)$ dapat dihitung dengan persamaan (10) sedangkan nilai koefisien perpindahan panas sisi shell dihitung dengan persamaan (11). Nilai A merupakan heat transfer area.

$$
\begin{gathered}
h i=\frac{q_{c}}{A \Delta T_{m}} \\
\text { ho }=\frac{q_{h}}{A \Delta T_{m}}
\end{gathered}
$$




\section{HASIL DAN DISKUSI}

Data eksperimen diperoleh dari pengambilan data laju massa, dan temperatur masuk dan keluar fluida sebelum dilakukan beberapa perhitungan variabel seperti: besar perpindahan panas, koefisien perpindahan panas, dan efektivitas dari heat exchanger. Simulasi CFD bertujuan untuk mengetahui variabel-variabel tersebut di atas dengan metode numerik. Hasil dari eksperimen dibandingkan dengan simulasi CFD untuk mendukung analisis karakteristik aliran STHX.

Tabel 1. Data Eksperimen dan Simulasi dengan Konfigurasi Baffle Jenis Single Segmental (Baffle Spacing $10 \mathrm{~cm}$ )

\begin{tabular}{|c|c|c|c|c|c|c|c|c|}
\hline \multirow[b]{2}{*}{$\begin{array}{c}\text { Laju } \\
\text { Massa } \\
(\mathrm{kg} / \mathrm{s})\end{array}$} & \multicolumn{4}{|c|}{ Hasil Eksperimen } & \multicolumn{4}{|c|}{ Hasil Simulasi } \\
\hline & $\begin{array}{c}\text { Temperatur } \\
\text { outlet shell } \\
\left({ }^{\circ} \mathrm{C}\right)\end{array}$ & $\begin{array}{c}\text { Temperatur } \\
\text { outlet tube } \\
\left({ }^{\circ} \mathrm{C}\right)\end{array}$ & $\begin{array}{c}\text { Total } \\
\text { heat } \\
\text { transfer } \\
\text { coeff. } \\
\left(\mathrm{W} / \mathbf{m}^{2} . \mathrm{K}\right)\end{array}$ & Efektivitas & $\begin{array}{c}\text { Temperatur } \\
\text { outlet tube } \\
\left({ }^{\circ} \mathrm{C}\right)\end{array}$ & $\begin{array}{c}\text { Temperatur } \\
\text { outlet shell } \\
\left({ }^{\circ} \mathrm{C}\right)\end{array}$ & $\begin{array}{c}\text { Total } \\
\text { heat } \\
\text { transfer } \\
\text { coeff. } \\
\left(\mathrm{W} / \mathbf{m}^{2} . \mathrm{K}\right)\end{array}$ & Efektivitas \\
\hline 0,033 & 41 & 40 & 155 & 0,52 & 44 & 44 & 68 & 0,50 \\
\hline 0,066 & 38 & 41 & 194 & 0,45 & 42 & 46 & 123 & 0,45 \\
\hline 0,099 & 36 & 4 & 210 & 0,40 & 40 & 47 & 167 & 0,39 \\
\hline 0,133 & 35 & 42 & 241 & 0,39 & 39 & 49 & 197 & 0,34 \\
\hline 0,166 & 35 & 42 & 301 & 0,39 & 38 & 50 & 224 & 0,31 \\
\hline
\end{tabular}

Tabel 2. Data Eksperimen dan Simulasi dengan Konfigurasi Baffle Jenis Single Segmental (Baffle Spacing $5 \mathrm{~cm}$ )

\begin{tabular}{|c|c|c|c|c|c|c|c|c|}
\hline \multirow[b]{2}{*}{$\begin{array}{c}\text { Laju } \\
\text { Massa } \\
(\mathrm{kg} / \mathrm{s})\end{array}$} & \multicolumn{4}{|c|}{ Hasil Eksperimen } & \multicolumn{4}{|c|}{ Hasil Simulasi } \\
\hline & $\begin{array}{l}\text { Temperatur } \\
\text { outlet shell } \\
\left({ }^{\circ} \mathrm{C}\right)\end{array}$ & $\begin{array}{c}\text { Temperatur } \\
\text { outlet tube } \\
\left({ }^{\circ} \mathrm{C}\right)\end{array}$ & \begin{tabular}{|c|} 
Total \\
heat \\
transfer \\
coeff. \\
$\left(\mathrm{W} / \mathrm{m}^{2} . \mathrm{K}\right)$
\end{tabular} & Efektivitas & $\begin{array}{l}\text { Temperatur } \\
\text { outlet tube } \\
\left({ }^{\circ} \mathrm{C}\right)\end{array}$ & $\begin{array}{l}\text { Temperatur } \\
\text { outlet shell } \\
\quad\left({ }^{\circ} \mathrm{C}\right)\end{array}$ & $\begin{array}{c}\text { Total } \\
\text { heat } \\
\text { transfer } \\
\text { coeff. } \\
\left(\mathrm{W} / \mathrm{m}^{2} . \mathrm{K}\right)\end{array}$ & Efektivitas \\
\hline 0,033 & 39 & 40 & 85 & 0,49 & 45 & 43 & 74 & 0,52 \\
\hline 0,066 & 38 & 41 & 198 & 0,46 & 43 & 45 & 136 & 0,47 \\
\hline 0,099 & 36 & 42 & 348 & 0,41 & 42 & 47 & 186 & 0,42 \\
\hline 0,133 & 36 & 43 & 516 & 0,39 & 41 & 48 & 226 & 0,38 \\
\hline 0,166 & 34 & 43 & 651 & 0,37 & 40 & 49 & 261 & 0,35 \\
\hline
\end{tabular}

Tabel 3. Data Eksperimen dan Simulasi dengan Konfigurasi Baffle Jenis Triple Segmental

\begin{tabular}{|c|c|c|c|c|c|c|c|c|}
\hline \multirow[b]{2}{*}{$\begin{array}{c}\text { Laju } \\
\text { Massa } \\
(\mathrm{kg} / \mathrm{s})\end{array}$} & \multicolumn{4}{|c|}{ Hasil Eksperimen } & \multicolumn{4}{|c|}{ Hasil Simulasi } \\
\hline & \begin{tabular}{|l|} 
Temperatur \\
outlet shell \\
$\left({ }^{\circ} \mathrm{C}\right)$
\end{tabular} & $\begin{array}{c}\text { Temperatur } \\
\text { outlet tube } \\
\left({ }^{\circ} \mathrm{C}\right)\end{array}$ & $\begin{array}{c}\text { Total } \\
\text { heat } \\
\text { transfer } \\
\text { coeff. } \\
\left(\mathrm{W} / \mathrm{m}^{2} . \mathrm{K}\right)\end{array}$ & Efektivitas & $\begin{array}{l}\text { Temperatur } \\
\text { outlet tube } \\
\left({ }^{\circ} \mathrm{C}\right)\end{array}$ & $\begin{array}{c}\text { Temperatur } \\
\text { outlet shell } \\
\left({ }^{\circ} \mathrm{C}\right)\end{array}$ & $\begin{array}{c}\text { Total } \\
\text { heat } \\
\text { transfer } \\
\text { coeff. } \\
\left(\mathrm{W} / \mathrm{m}^{2} . \mathrm{K}\right)\end{array}$ & Efektivitas \\
\hline 0,033 & 38 & 39 & 114 & 0,48 & 43 & 45 & 63 & 0,48 \\
\hline 0,066 & 37 & 41 & 171 & 0,44 & 42 & 46 & 119 & 0,44 \\
\hline 0,099 & 36 & 42 & 209 & 0,40 & 41 & 47 & 165 & 0,39 \\
\hline 0,133 & 35 & 42 & 240 & 0,39 & 40 & 49 & 200 & 0,36 \\
\hline
\end{tabular}




\begin{tabular}{|l|l|l|l|l|l|l|l|l|}
\hline 0,166 & 35 & 43 & 284 & 0,37 & 39 & 50 & 230 & 0,33 \\
\hline
\end{tabular}

\subsection{Variasi Jenis Baffle}

Hasil penelitian dengan variasi jenis baffle ditampilkan dengan dua variabel pendukung yaitu koefisien perpindahan panas total dan efektivitas yang masing-masing terhadap fungsi laju massa.

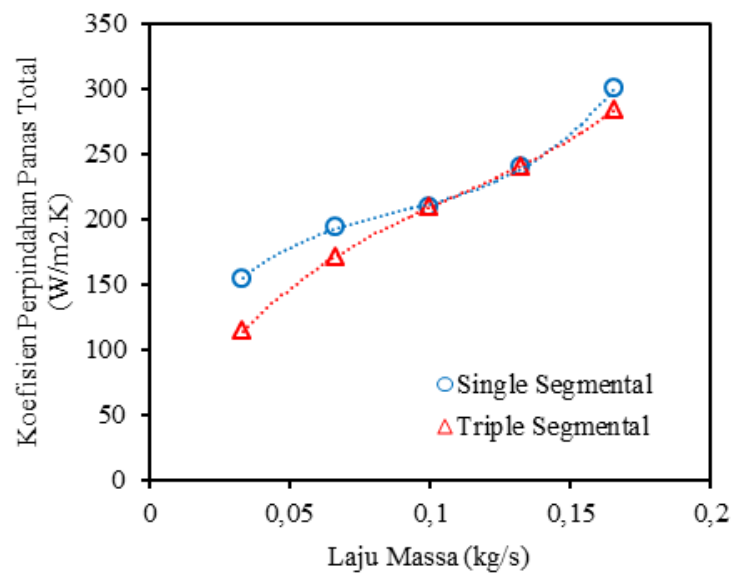

(a)

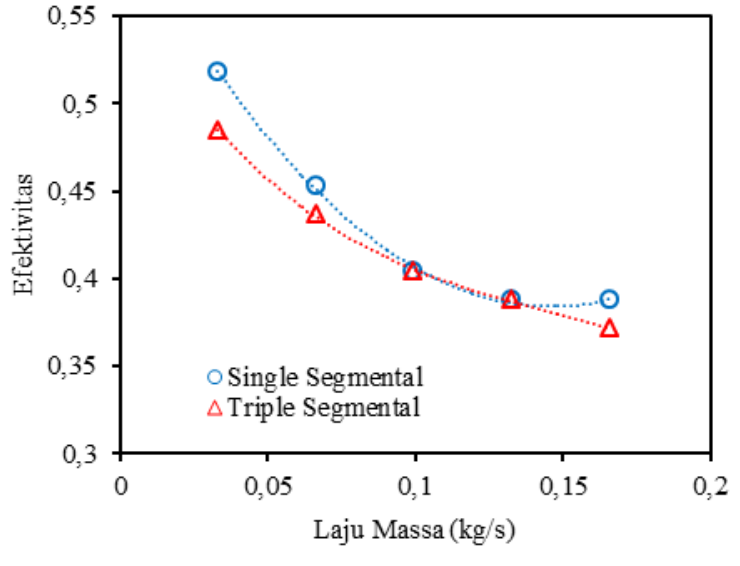

(b)

Gambar 3. (a) Grafik hubungan koefisien perpindahan panas total terhadap laju massa

(b) Grafik efektivitas fungsi laju massa

Hubungan koefisien perpindahan panas total terhadap laju massa ditunjukkan pada Gambar 3 (a). Kedua grafik memiliki trend yang sama yaitu koefisien perpindahan panas total semakin meningkat seiring dengan peningkatan laju massa baik saat menggunakan baffle single segmental maupun saat menggunakan baffle triple segmental. Nilai koefisien perpindahan panas total dipengaruhi oleh koefisien perpindahan panas sisi shell dan tube dimana nilai $h_{i}$ dan $h_{o}$ sama maka $U$ bernilai sama pada saat laju massa $0,099 \mathrm{~kg} / \mathrm{s}$ dan saat $0,133 \mathrm{~kg} / \mathrm{s}$.

Pada baffle single segmental, nilai koefisien perpindahan panas total relatif lebih tinggi jika dibandingkan saat menggunakan baffle triple segmental. Nilai koefisien perpindahan panas total terrendah saat menggunakan baffle single segmental adalah $155 \mathrm{~W} / \mathrm{m}^{2} . \mathrm{K}$ sedangkan nilai tertinggi sebesar $301 \mathrm{~W} / \mathrm{m}^{2} . \mathrm{K}$ atau mengalami kenaikan sebesar $94 \%$. Sedangkan pada saat heat exchanger menggunakan baffle jenis triple segmental koefisien perpindahan panas total mengalami kenaikan sebesar $149 \%$ dari $114 \mathrm{~W} / \mathrm{m}^{2} . \mathrm{K}$ ke 284 $\mathrm{W} / \mathrm{m}^{2} . \mathrm{K}$.

Gambar 3 (b) menunjukkan bahwa efektivitas STHX mengalami penurunan saat terjadi kenaikan laju massa di sisi shell maupun di sisi tube. Efektivitas heat exchanger saat menggunakan baffle single segmental lebih baik jika dibandingkan dengan efektivitas saat menggunakan baffle triple segmental. Nilai efektivitas yang tertinggi dan terendah saat menggunakan baffle single segmental adalah 0,52 dan 0,39 sedangkan saat menggunakan baffle triple segmental bernilai 0,48 dan 0,37. Penurunan efektivitas STHX diakibatkan oleh heat transfer area yang rendah sehingga perpindahan panas rendah. Perpindahan panas yang baik ditandai dengan penurunan temperatur yang besar.

\subsection{Variasi Jarak Antar Baffle}

Gambar 4 (a) menunjukan bahwa semakin besar nilai laju massa, maka semakin besar pula nilai koefisien perpindahan panas total. Nilai koefisien perpindahan panas total dengan baffle spacing $5 \mathrm{~cm}$ memiliki nilai maksimal $651 \mathrm{~W} / \mathrm{m}^{2} . K$ sedangkan dengan baffle spacing $10 \mathrm{~cm}$ sebesar $363 \mathrm{~W} / \mathrm{m}^{2} . K$. STHX yang menggunakan baffle spacing

93 JURNAL ILMU FISIKA (JIF), VOL 8 NO 2, SEPTEI 
lebih kecil dengan laju massa yang sama, memiliki koefisien perpindahan kalor total lebih besar.

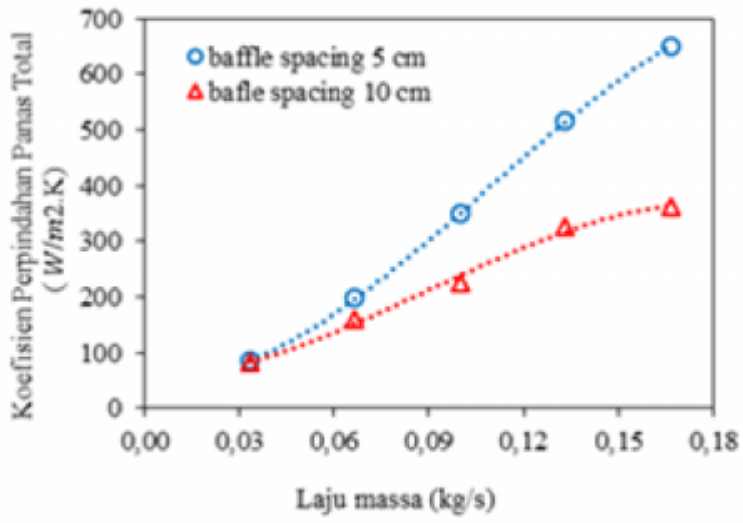

(a)

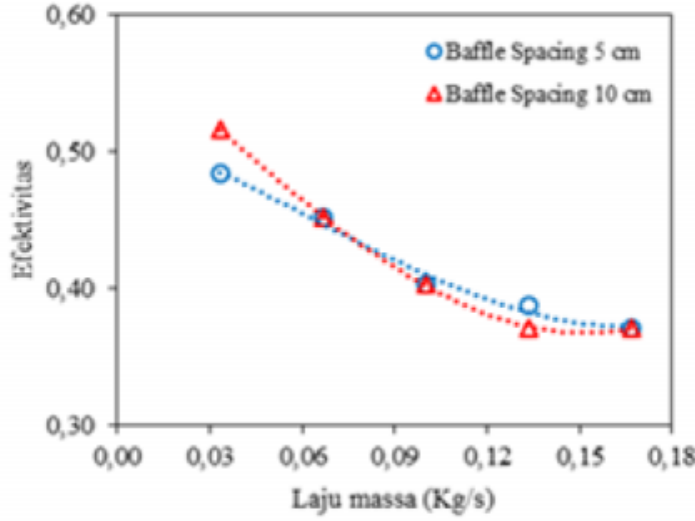

(b)

Gambar 4. (a) Grafik Hubungan Koefisien Perpindahan Panas Total terhadap Laju Massa pada Variasi Jarak Antar Baffle (b) Grafik Hubungan Efektivitas terhadap Laju Massa pada Variasi Jarak Antar Baffle

Gambar 4 (b) menunjukan pengaruh perubahan laju massa terhadap efektivitas. Efektivitas menurun seiring dengan kenaikan laju massa. Selisih terbesar terjadi saat laju massa minimal $0,033 \mathrm{~kg} / \mathrm{s}$, setelah itu selisih efektivitas mengecil seiring dengan kenaikan laju massa di sisi shell dan di sisi tube. Efektivitas tertinggi dan terendah saat menggunakan jarak antar baffle $5 \mathrm{~cm}$ bernilai 0,49 dan 0,37.

\subsection{Simulasi CFD}

Simulasi dilakukan pada software Solidworks Flow Simulation 2014. Turbulence model yang digunakan adalah Modified k- $\varepsilon$ serta Meshing technique yang dipilih adalah Immerse boundary Cartesian. Turbulence parameter simulasi adalah turbulent intensity $5 \%$ dan turbulence length 0,0024 m. Boundary Condition yang dipilih Inlet mass flow dan inlet profile uniform. Pada Gamber 5 dan 6, inlet air panas sisi shell berada di A, inlet air dingin sisi tube berada di a, outlet air panas sisi shell berada di $\mathrm{B}$, dan outlet air dingin sisi tube berada di $b$.

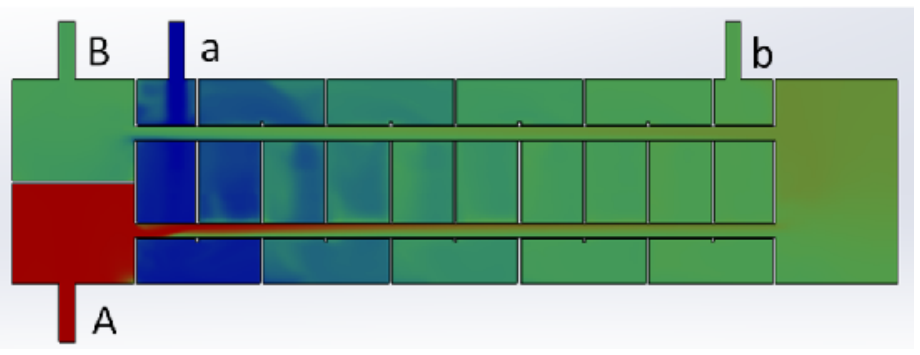

(a)

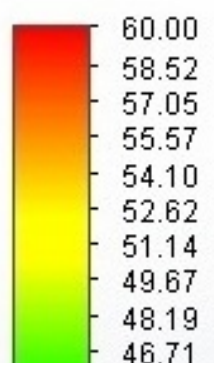




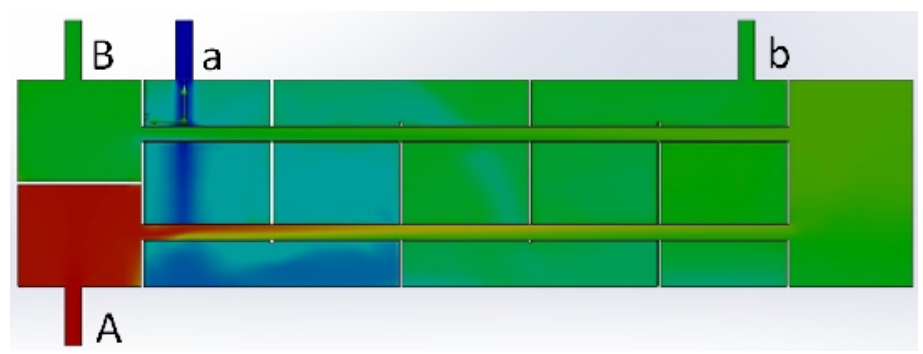

(b)

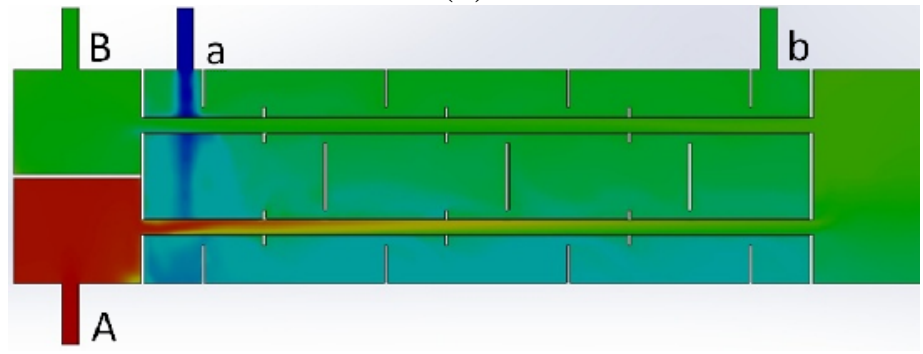

(c)

Gambar 5. Kontur temperatur pada beberapa konfigurasi baffle (a) baffle single segmental (jarak antar baffle $5 \mathrm{~cm}$ ); (b) baffle single segmental (jarak antar baffle $10 \mathrm{~cm}$ );

(c) konfigurasi baffle triple segmental

Kontur temperatur pada tiga konfigurasi baffle ditunjukkan pada Gambar 5. Kontur yang ditampilkan pada saat laju massa di sisi shell dan di sisi tube sebesar $0,033 \mathrm{~kg} / \mathrm{s}$. Pada kontur tersebut menunjukkan aliran fluida di sisi shell mengalami turbulensi aliran lebih besar karena struktur dari baffle single segmental, sementara pada konfigurasi baffle triple segmental aliran fluida di shell langsung menuju ke bawah dengan turbulensi yang tidak besar. Hal ini yang mengakibatkan nilai perpindahan panas pada konfigurasi baffle single segmental relatif lebih besar dibandingkan dengan konfigurasi baffle triple segmental.

Pada Gambar 6, kecepatan dan streamline pada variasi baffle spacing dan jenis baffle. Gambar 6 menunjukkan aliran mengalami percepatan setelah setelah melewati segmen baffle dengan beberapa zona resirkulasi terdapat di sekitar aliran primer. Aliran primer yang memberi kontribusi besar dalam koefisien perpindahan panas terlihat lebih jelas pada konfigurasi baffle single segmental terlihat dari pada aliran primer pada konfigurasi baffle triple segmental. Aliran primer ditandai dengan kontur kecepatan yang lebih tinggi dibandingkan dengan aliran di sekelilingnya dimana terdapat zona resirkulasi. Zona resirkulasi terlihat dari timbul aliran balik (backflow) dan vortex yang dapat menghambat. Zona resirkulasi berkurang seiring dengan yang berpengaruh terhadap peningkatan kenaikan kecepatan aliran. Hal ini dapat mengakibatkan kenaikan perpindahan panas. Zona resirkulasi pada konfigurasi baffle triple segmental lebih banyak ditemukan dibandingkan zona resirkulasi pada konfigurasi baffle single segmental. Hal ini yang menyebabkan proses perpindahan panas pada baffle single segmental lebih baik. 


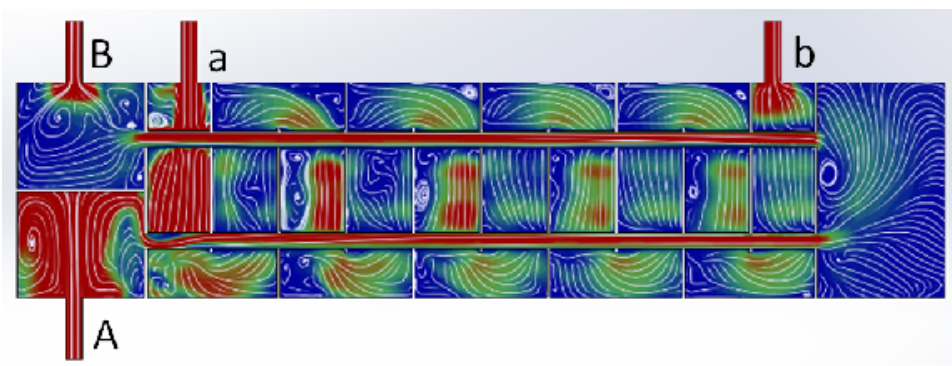

(a)

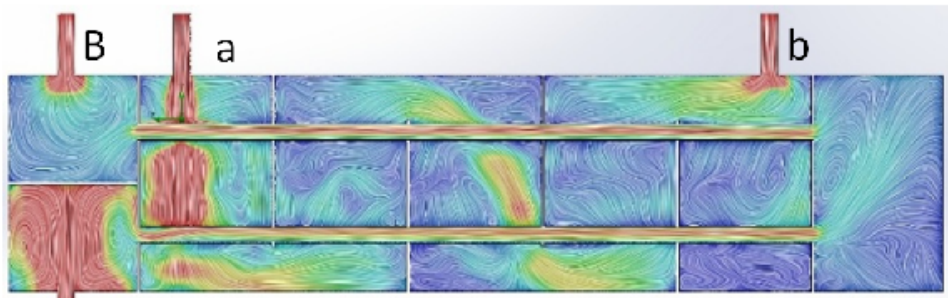

A

(b)
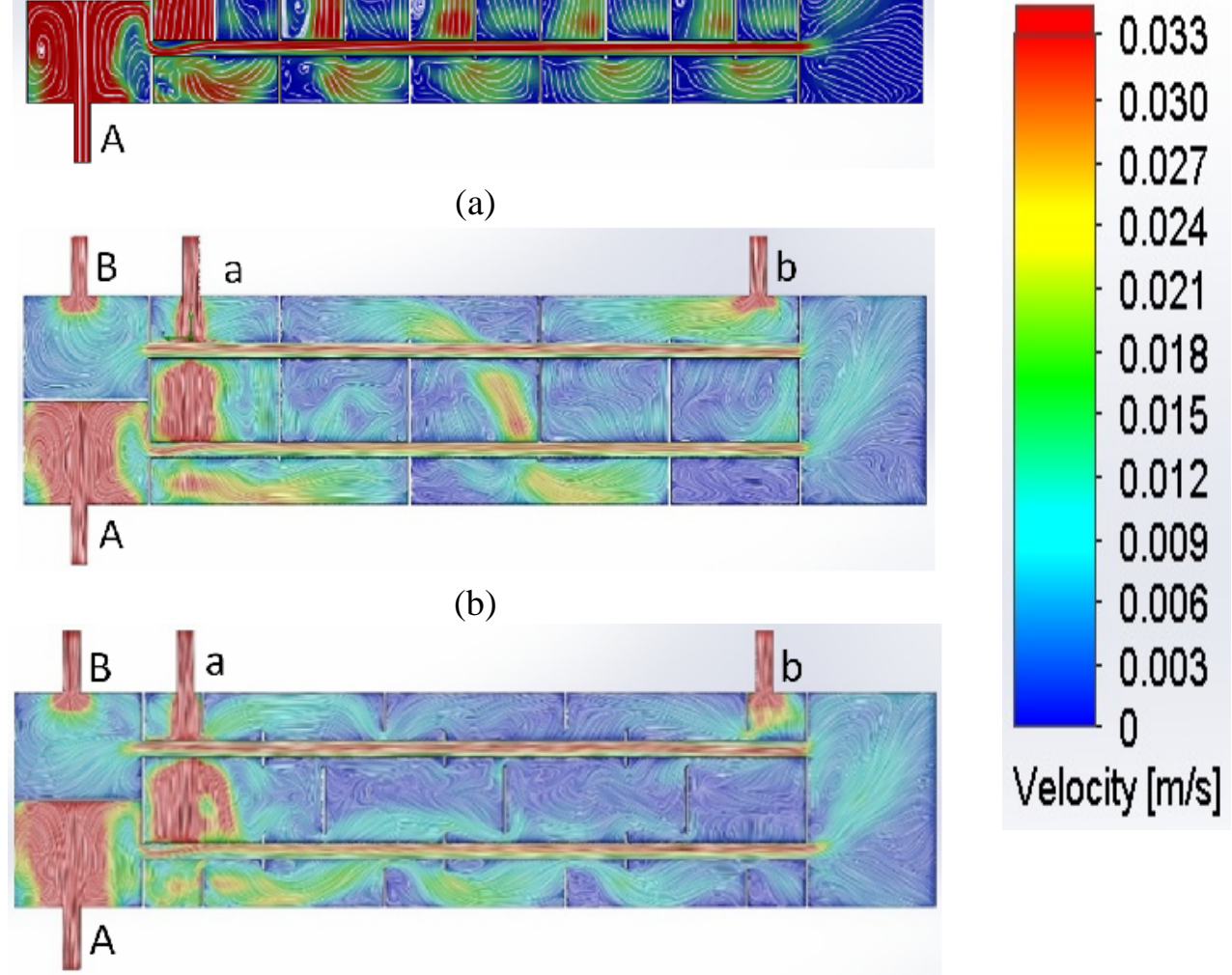

(c)

Gambar 6. Kontur kecepatan dan streamline pada beberapa konfigurasi baffle (a) baffle single segmental (jarak antar baffle $5 \mathrm{~cm}$ ); (b) baffle single segmental (jarak antar baffle $10 \mathrm{~cm}$ ); (c) baffle triple segmental

\section{KESIMPULAN}

- Eksperimen tentang perpindahan panas STHX dengan variasi jenis baffle (single segmental dan triple segmental) serta variasi baffle spacing $(5 \mathrm{~cm}$ dan $10 \mathrm{~cm})$ telah dilakukan.

- Hasil penelitian variasi pertama menunjukkan bahwa baik jenis baffle single segmental menghasilkan koefisien perpindahan panas total dan efektivitas yang lebih baik daripada baffle jenis triple segmental pada variasi yang sama. Trend kenaikan koefisien perpindahan panas total berbanding lurus dengan peningkatan laju massa sedangkan efektivitas berbanding terbalik dengan laju aliran massa. Adapun nilai maksimal $301 \mathrm{~W} / \mathrm{m}^{2} . \mathrm{K}$ saat laju massa $0,166 \mathrm{~kg} / \mathrm{s}$ sedangkan efektivitas bernilai maksimal 0,5 ketika laju massa $0,033 \mathrm{~kg} / \mathrm{s}$.

- Hasil variasi kedua menunjukkan baffle spacing $5 \mathrm{~cm}$ menghasilkan koefisien perpindahan panas total yang lebih tinggi jika dibandingkan dengan baffle spacing $10 \mathrm{~cm}$. Adapun nilai koefisien perpindahan panas total maksimal adalah $651 \mathrm{~W} / \mathrm{m}^{2} . \mathrm{K}$ saat laju massa $0,166 \mathrm{~kg} / \mathrm{s}$. Sedangkan pada efektivitas baffle spacing hanya menunjukkan performa yang lebih baik ketika laju massa lebih besar dari $0,133 \mathrm{~kg} / \mathrm{s}$. Adapun nilai tertinggi efektivitas terjadi saat baffle spacing $10 \mathrm{~cm}$ dengan nilai 0,52 saat laju massa $0,033 \mathrm{~kg} / \mathrm{s}$. 
- Hasil simulasi CFD baik kontur temperatur maupun kecepatan menunjukkan variasi baffle spacing $5 \mathrm{~cm}$ cenderung menghasilkan distribusi temperatur yang lebih merata baik disisi shell maupun disisi tube dikarenakan banyaknya turbulensi didalam shell sehingga dapat meningkatkan koefisien perpindahan panas total. Sedangkan variasi jenis baffle menunjukkan bahwa baffle single segmental menghasilkan turbulensi yang lebih baik jika dibandingkan baffle triple segmental sehingga dapat menghasilkan efektivitas dan koefisien perpindahan panas total tinggi.

\section{DAFTAR PUSTAKA}

1. Master, B.I., Chunangad, K.S., Pushpanathan, V. 2003, Fouling mitigation using helixchanger heat exchangers, Proceedings of the ECI Conference on Heat Exchanger Fouling and Cleaning: Fundamentals and Applications, 317-322.

2. Bell, K.J., Delaware method for shell side design, In: S. Kakac, A.E. Bergles, F. Mayinger, 1981, Eds. Heat Exchangers-Thermal-Hydraulic Fundamentals and Design, Taylor \& Francis, Washington, 343-375

3. Bell, K.J., Delaware method of shell side design, in: S. Kakac, A.E. Bergles, F. Mayinger (Eds.) 1986, Heat Exchanger Sourcebook, Hemisphere, New York, 159-200

4. Bell, K.J., Delaware method of shell-side design, in: R.K. Shah, E.C. Sunnarao, R.A. Mashelkar (Eds.), 1988, Heat Transfer Equipment Design, Taylor \& Francis, New York, 145-166

5. Bell, K.J., 2004, Heat exchanger design for the process industries, ASME J. Heat Transfer 126, 877-885

6. Serth, R. W. 2007, Process Heat Transfer Principles and Applications, Academic Press, Oxford.

7. Šoljic dkk., 2009, Vibration Analysis of Heat Exchangers of Nitric Acid Plant, Chem. Biochem. Eng. Q. 23, 287-294

8. Ardhiyangga, N., Ariwibowo, T. H., Permatasari, P.D., 2016, Numerical Study of Shell-And-Tube Heat Exchanger Characteristics in Laminar Flow with Single Segmental Baffle, Prosiding Seminar Nasional Teknik Kimia "Kejuangan", C51C57.

9. Triyono, S., Ariwibowo, T. H., Permatasari, P.D., 2016, Numerical Study of Shell-And-Tube Heat Exchanger Performance with Various Baffle Spacing, Prosiding Seminar Nasional Teknik Kimia “Kejuangan”, C41-C47 